Check for updates

Cite this: RSC Adv., 2018, 8, 39937

Received 19th October 2018

Accepted 15th November 2018

DOI: $10.1039 / \mathrm{c} 8 \mathrm{ra0} 0664 \mathrm{~h}$

rsc.li/rsc-advances

\section{A novel porous carbon material derived from the byproducts of bean curd stick manufacture for high-performance supercapacitor use $\uparrow$}

\begin{abstract}
Lulu Shi, ${ }^{a}$ Lihua Jin, (D) *a Zheng Meng, ${ }^{a}$ Yanan Sun, ${ }^{a}$ Cong Li ${ }^{b}$ and Yehua Shen ${ }^{a}$
The exploitation of efficient renewable energy resources and the promotion of added value of agricultural products are always hot topics. In this study, we present a novel porous carbon material for high performance supercapacitor applications made from the byproduct of bean curd stick manufacture. The as-prepared carbon material possesses a hollow interconnected structure with a large specific surface area $\left(2609 \mathrm{~m}^{2} \mathrm{~g}^{-1}\right)$, while containing $5.01 \%$ oxygen and $1.75 \%$ nitrogen heteroatoms. Therefore, besides electrical double-layer capacitance, it can also produce additional pseudocapacitance to enhance the overall capacitance. Benefiting from these advantages of structure and composition, the bean curd stick based porous carbon material demonstrates a high specific capacitance of $405 \mathrm{~F} \mathrm{~g}^{-1}$ at $0.5 \mathrm{~A} \mathrm{~g}^{-1}$. Moreover, the presented porous carbon material based symmetric supercapacitor also offers a high energy density (11.35 W h kg-1 at a power density of $125 \mathrm{~W} \mathrm{~kg}^{-1}$ ). All the above findings indicate that the byproduct of bean curd stick manufacture is an excellent optional material for preparing highperformance supercapacitor material. Simultaneously, this work also provides an effective strategy for adding value to agricultural products.
\end{abstract}

\section{Introduction}

In recent years, owing to the growing demands for energy and the exhausting of traditional fossil energy, the exploitation of efficient renewable energy resources has become extremely urgent and important. ${ }^{1-4}$ Scholars and researchers around the world are trying to explore and develop biomass energy to replace fossil energy. Supercapacitors, as electrochemical energy storage devices, have been a hot research topic because of their excellent electrochemical properties, such as high power density, fast charge/discharge rate and excellent cycle stability. ${ }^{5,6}$ In the light of the energy storage mechanism of capacitors, supercapacitors can be roughly divided into two categories: pseudocapacitors and electrical double-layer capacitors (EDLCs). ${ }^{7}$ Conventionally, the energy storage of pseudocapacitors is primarily dominated by the quasi Faraday capacitance produced by redox reaction, ${ }^{\mathbf{8}, 9}$ while the capacitance generation of EDLCs generally arises from the behavior of electrostatic charge diffusion and accumulation at the

${ }^{a}$ Key Laboratory of Synthetic and Natural Functional Molecule Chemistry of the Ministry of Education, College of Chemistry \& Materials Science, Northwest University, Xi'an 710127, People's Republic of China. E-mail: jinlihua@nwu.edu.cn; Fax: +86-029-88302635

${ }^{b}$ National Demonstration Center for Experimental Chemistry Education, Northwest University, Xi'an 710127, People's Republic of China

$\dagger$ Electronic supplementary information (ESI) available. See DOI: 10.1039/c8ra08664h interface of electrode/electrolyte. ${ }^{10-13}$ Contrastingly, pseudocapacitors possess high capacitance, and EDLCs exhibit a higher power density and more excellent cyclic performance. There are merits to both the two supercapacitor types. Therefore, the exploration and development of a comprehensive supercapacitor that allows the two types to intermingle without losing their separate merits is a marvelous way to get a higher-performance supercapacitor.

As we all know, the characteristics of electrode materials play an important part in the performance of a supercapacitor. Therefore, a tremendous amount of effort has been focused on developing innovative supercapacitor materials with high capacitance and excellent cycle stability. Biomass-derived porous carbon materials are a typical promising candidate for supercapacitors. ${ }^{14,15}$ They not only overcome non-renewable/ high cost disadvantages as compared with graphene or carbon nanotubes, but also possess advantages including large specific surface area and high energy storage capability. ${ }^{10,16} \mathrm{Up}$ to now, various biomass-based porous carbon materials derived from leaves, ${ }^{17,18}$ bamboo, ${ }^{19-22}$ egg yolk, ${ }^{23}$ fungus ${ }^{24-26}$ and bean products $^{27-30}$ have been widely used in the electrodes of supercapacitors. However, most of the existing biomass-based electrode materials have the characteristics of low capacitance and poor cycle stability. Therefore, it is still important to explore simple synthesis processes to develop different carbon electrode materials with excellent supercapacitor properties.

Bean curd stick is a traditional Chinese food that is made from soya beans. Weight for weight it contains more protein 
than soya bean, bean curd, or bean dregs; its protein content can even reach $45-50 \%$. Bean curd stick is usually processed into dried strip products, and during the manufacturing process, byproducts are usually produced. The tons of slag material left over from bean curd stick manufacture are at present discharged as agro-industrial waste or used as animal fodder. Therefore, the exploration of a feasible approach to further improve the added value of bean curd stick manufacture will obviously increase economic efficiency of the processing plant. Referring to previous studies, ${ }^{23,26}$ doping porous carbon materials with nitrogen atoms can remarkably improve their capacitive behavior. And an effective and feasible method to fabricate nitrogen-functionalized porous carbon materials is to directly carbonize high protein content biomass, such that the nitrogen is incorporated firmly in the carbon frame. Therefore, all the bean byproducts that are rich in $\mathrm{C}$ and $\mathrm{N}$ elements are considered to be good candidates for making high added value heteroatom-doped carbon materials. Recently, many active carbon based electrode materials for supercapacitors derived from soya bean, bean curd, or bean dregs have been made. For example, Ma and his co-workers synthesized a nitrogen-doped porous carbon from bean dregs which could be used as electrode material for supercapacitors. ${ }^{27}$ Cao and his group also prepared a kind of onedimensional (1D) carbon nanobelt from bean curd for high specific capacitance $\left(262 \mathrm{~F} \mathrm{~g}^{-1}\right.$ at $0.5 \mathrm{~A} \mathrm{~g}^{-1}$ ) supercapacitors. ${ }^{28}$ Recently, Wang and his group also reported functionalized porous carbon from soybean root for supercapacitors. ${ }^{29}$ All the mentioned researches clearly demonstrated that bean products are promising carbonaceous raw material for supercapacitor electrodes. However, until now, no relative reports have appeared that study the application of bean curd stick in supercapacitor materials. Judging purely by the content of available components, such as the content of protein, bean curd stick based supercapacitor electrode materials are suspected to possess great performance as supercapacitors because of their abundant protein content, which can provide much more effective heteroatom doping and additional pseudocapacitance from the redox reaction. ${ }^{15,31}$

Herein, enlightened by this conjecture, we present a facile method to synthesize heteroatom-doped interconnected porous carbon electrode material by using the byproducts of bean curd stick biomass as carbon precursor and nitrogen source. Through a process of hydrothermal carbonization, precarbonization and activation with $\mathrm{KOH}$, active carbon materials were synthesized. It was no accident that the selected asprepared porous carbon material exhibited a well-developed interconnected pore structure with a specific surface area as high as $2609 \mathrm{~m}^{2} \mathrm{~g}^{-1}$. Moreover, as an electrode material, it also exhibited fine capacitive performance with relatively high specific capacitance (405 $\mathrm{F} \mathrm{g} \mathrm{g}^{-1}$ at a current density of $0.5 \mathrm{~A} \mathrm{~g}^{-1}$ ), favorable rate performance and good cycling stability. Generally, the electrochemical performance of the present porous carbon material is much better than that of the existing commercial porous carbons and most other nitrogendoped carbon materials.

\section{Experimental section}

\subsection{Materials}

Fresh slag material from bean curd stick was purchased from a local bean curd stick food processing workshop (Yuan Village, Xianyang, China). Acetone, ethanol and potassium hydroxide were bought from Sinopharm Chemical Reagent Co. Ltd (China). Polytetrafluoroethylene (PTFE) solution (60\%) and acetylene black were obtained from Daikin, Japan Co., Ltd (Japan). NKK-MPF30AC-100 aqueous separator was provided by NKK, Japan Co., Ltd (Japan). Nickel foam $(1.5 \mathrm{~cm} \times 1 \mathrm{~cm})$ was obtained from Changde Lyrun Material Co., Ltd (Hunan, China).

\subsection{Preparation of bean curd stick derived porous carbon materials}

In a typical synthesis, the fresh slag material from bean curd stick was firstly pounded into a fine powder in a mortar. Subsequently, $12 \mathrm{~g}$ bean curd stick powder and $60 \mathrm{~mL}$ deionized water were put into a Teflon-lined autoclave for hydrothermal treatment at $200{ }^{\circ} \mathrm{C}$ for $6 \mathrm{~h}$. A brown hydrothermal product was collected and freeze-dried at $-40{ }^{\circ} \mathrm{C}$. After that, the obtained product was activated with $\mathrm{KOH}$ through resistance furnace heating. The compound was first pyrolyzed in a tubular furnace (400 ${ }^{\circ} \mathrm{C}$ for 1 hour, $700{ }^{\circ} \mathrm{C}$ for another 1 hour; heating rate of $10{ }^{\circ} \mathrm{C} \min ^{-1} ; \mathrm{N}_{2}$ atmosphere). Finally, the samples were centrifuged with $1 \mathrm{M}$ hydrochloric acid and distilled water until they reached neutral $\mathrm{pH}$. The residue was collected and dried in a vacuum drying chamber at $80{ }^{\circ} \mathrm{C}$. For control experiments, different carbonization temperatures $\left(600{ }^{\circ} \mathrm{C}, 700{ }^{\circ} \mathrm{C}, 800{ }^{\circ} \mathrm{C}\right)$ and different weight ratios between carbonaceous samples and $\mathrm{KOH}(1: 0,1: 1,1: 2,1: 3)$ were investigated, and different products, named 700-0, 700-1, 700-2, 700-3, 600-3, 800-3, were obtained.

\subsection{Characterization}

The micromorphology of materials was characterized by scanning electron microscopy (SEM; SU8010, Hitachi Co.) and transmission electron microscopy (TEM; FEI Tecnai G2 F20). The crystal structure was determined by X-ray diffraction (XRD; AXS-D8, Bruker). The Raman spectra were analyzed using a laser Raman spectrometer (DXR2, Thermo Electron Co.). The surface elemental composition was examined by X-ray photoelectron spectroscopy (XPS; AXIS ULTRA). $\mathrm{N}_{2}$ adsorption-desorption isotherms were obtained at $77 \mathrm{~K}$ to assess specific surface area and porosity (Tri Star-3020, Micromeritics Instrument Co.). Electrochemical testing was performed on a CHI 660D electrochemical workstation (Chenhua).

\subsection{Electrochemical measurements}

The working electrode of the bean curd stick based porous carbon material (C-BCS) for supercapacitor devices was prepared as follows: a weight ratio of $85: 10: 5$ mixture of carbon material, acetylene black and PTFE binder was pressed on a nickel foam current collector. The loaded electrode was 
(a)

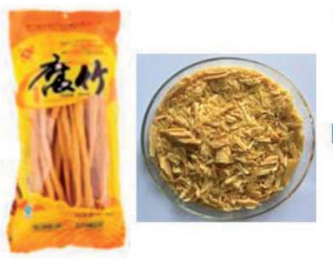

Hydrothermal

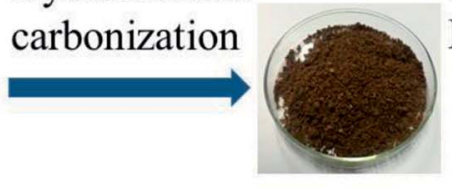

Pyrolyzation \&

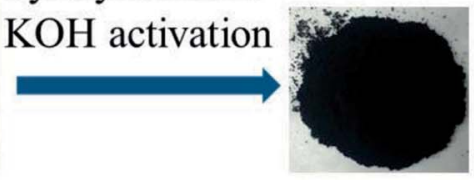

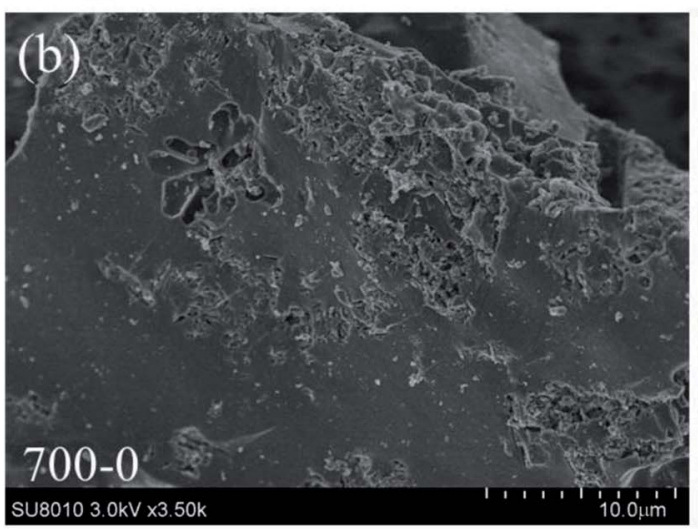
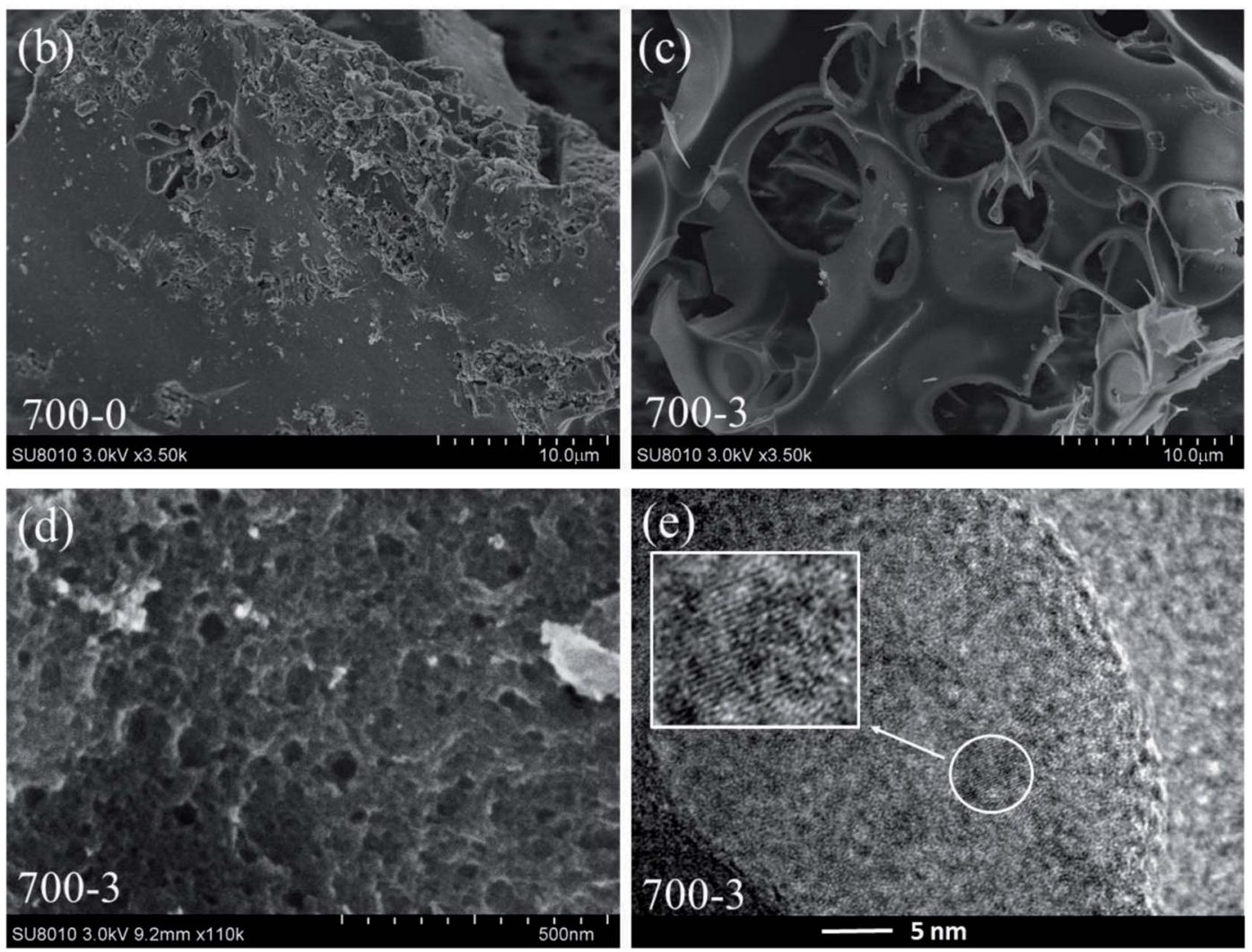

Fig. 1 (a) Schematic diagram of the synthesis route of bean curd stick derived porous carbon; and SEM images of (b) the 700-0 sample, and (c and d) the 700-3 sample at different magnifications; (e) TEM image of the 700-3 sample.

dried at $80{ }^{\circ} \mathrm{C}$ overnight and pressed under $10 \mathrm{MPa}$ for 30 seconds; the mass loading of active material was $c a .2 \mathrm{mg} \mathrm{cm}^{-1}$. The electrochemical measurements, such as cyclic voltammetry tests (CV), galvanostatic charge/discharge measurements (GCD) and electrochemical impedance spectroscopy tests (EIS), were performed in $6 \mathrm{M} \mathrm{KOH}$ electrolyte. The specific capacitance $\left(C_{\mathrm{g}}\right)$ of the present electrode in a three-electrode system was calculated from the charge/discharge curve by using eqn (1). In the 700-3 based symmetrical supercapacitor device, the two electrodes were separated by an MPF30AC-100 membrane which was soaked with $6 \mathrm{M} \mathrm{KOH}$ electrolyte. The specific capacitance $\left(C_{\text {cell }}, \mathrm{F} \mathrm{g}^{-1}\right)$, specific energy density $\left(E, \mathrm{~W} \mathrm{~h} \mathrm{~kg}^{-1}\right)$ and specific power density $\left(P, \mathrm{~W} \mathrm{~kg}^{-1}\right)$ of the device were calculated by the following eqn (2)-(4), respectively.

$$
\begin{gathered}
C_{\mathrm{g}}=\frac{I \times \Delta t}{m \times \Delta V} \\
C_{\text {cell }}=\frac{I \times \Delta t}{M \times \Delta V}
\end{gathered}
$$

$$
\begin{gathered}
E=\frac{1}{7.2} \times C_{\text {cell }} \times(\Delta V)^{2} \\
P=\frac{3600 \times E}{\Delta t}
\end{gathered}
$$

where $I$ defines the applied current, $\Delta t$ is the discharge time, $m$ represents the loading mass of electrode material on the single electrode, $\Delta V$ refers to the voltage window, and $M$ is the total mass of electrode material on the two electrodes, respectively.

\section{Results and discussion}

\subsection{Material characterization}

The detailed preparation process of the bean curd stick based porous carbon materials (C-BCS) is described in Fig. 1a. There were three main steps: hydrothermal carbonization (HTC), precarbonization and $\mathrm{KOH}$ chemical activation. Bean curd stick is a smooth, dry product, and it is difficult to directly and efficiently make it interact with $\mathrm{KOH}$ to obtain a porous carbon 
structure. Therefore, we adopted hydrothermal carbonization in the synthesis procedure in order to get a better product with higher throughput and specific surface area. Besides that, owing to the high protein content of bean curd stick, the hydrothermal product exhibited absorbed moisture, and could not be directly dried in a simple oven (as shown in the Fig. S1†). Thus, we chose to use freeze-drying technology. It not only effectively dries the sample, but also leads to the formation of a foamy powder structure, which is expected to be beneficial to the formation of more pore structures and increase the specific surface area. Moreover, it should also be noted that both the $\mathrm{KOH}$ activation and the pyrolyzing temperature play a critical role in the generation of the pore structure during the procedure. Therefore, we systematically investigated the influence of the amount of $\mathrm{KOH}$ added and the activation temperature on the formation of pores. As shown in Fig. S2, $\uparrow$ the C-BCS gradually turns into $3 \mathrm{D}$ interconnected pore structure with the increase of $\mathrm{KOH}$ activator content. Considering the electrochemical and structural properties of the synthesized samples, the C-BCS that was produced using an activation weight ratio (carbon : $\mathrm{KOH}$ ) of $1: 3$ with carbonization at $700{ }^{\circ} \mathrm{C}(700-3)$ was selected as the optimal sample for further supercapacitor applications.

Comparing the changes of morphology of the prepared CBCS before and after $\mathrm{KOH}$ activation, it could be clearly observed that hydrothermal carbonization treated carbon materials without $\mathrm{KOH}$ activation manifested their massive structure, and only some small holes existed on the surface (Fig. 1b). But after being treated with $\mathrm{KOH}$ in a weight ratio of $1: 3$, plenty of $3 \mathrm{D}$ architecture with interconnected macropores and cavities (in the range of sub-micrometer to a few micrometers) were discovered (Fig. 1c and d). The presence of such structure might be ascribed to pore-forming by $\mathrm{KOH}$ etching and the emission of $\mathrm{H}_{2}, \mathrm{CO}$ and $\mathrm{CO}_{2}$ from the chemical reactions at high temperature $\left(>400{ }^{\circ} \mathrm{C}\right)$ as follows: ${ }^{14,15,32,33}$

$$
\begin{gathered}
6 \mathrm{KOH}+2 \mathrm{C} \rightarrow 2 \mathrm{~K}+3 \mathrm{H}_{2}+2 \mathrm{~K}_{2} \mathrm{CO}_{3} \\
\mathrm{~K}_{2} \mathrm{CO}_{3} \rightarrow \mathrm{K}_{2} \mathrm{O}+\mathrm{CO}_{2} \\
\mathrm{~K}_{2} \mathrm{CO}_{3}+2 \mathrm{C} \rightarrow 2 \mathrm{~K}+3 \mathrm{CO}
\end{gathered}
$$

The formation of the porous carbon material is suspected to be helpful for full access of electrolyte ions to the charge storage sites and greatly improve its supercapacitor performance. ${ }^{11}$ High resolution TEM (HRTEM) imaging further confirmed the existence of partial graphitization on the surface of the 700-3 porous carbon material by the distorted lattice fringe morphology (Fig. 1e). According to previous reports, the degree of graphitization is another crucial indicator for excellent capacitive performance, which suggests that the porous carbon materials possess great electrical conductivity, and is highly beneficial to the charge transfer. ${ }^{22}$

Moreover, the degree of carbonization and graphitization of the 700-3 sample was also characterized by the XRD pattern and Raman spectroscopy. As shown in Fig. 2a, well-developed diffraction of plane (002) and weak diffraction of plane (100) of the disordered carbon layer can be observed, indicating the formation of a certain degree of graphite crystallite structure. ${ }^{22,34}$ In the Raman spectrum (Fig. 2b), two bands of carbon materials ascribed to the $\mathrm{D}$ (defects and disorder) band (1348 $\mathrm{cm}^{-1}$ )and $\mathrm{G}$ (graphitic) band $\left(1584 \mathrm{~cm}^{-1}\right.$ ) can also be observed, ${ }^{35}$ and the smaller the intensity ratio $\left(I_{\mathrm{D}} / I_{\mathrm{G}}\right)$ of the $\mathrm{D}$ and $\mathrm{G}$ bands, the higher the degree of graphitization of carbon material. In our case, the intensity ratio $\left(I_{\mathrm{D}} / I_{\mathrm{G}}\right)$ of $700-3$ porous carbon materials was calculated to be 0.88 , which is comparable to or much lower than many other biomass-derived porous carbon materials, such as those from kiwifruit $(0.93),{ }^{36}$ bean dregs (0.97), ${ }^{27}$ waste coffee grounds (1.00), ${ }^{37}$ bamboo-based byproduct (1.01), ${ }^{22}$ auricularia (1.02), ${ }^{26}$ Jujun grass $(1.03)^{38}$ and human hair (1.23). ${ }^{39}$

In order to investigate the porosity of our prepared porous carbon materials, the nitrogen adsorption-desorption isotherms and pore size distributions were obtained at $77 \mathrm{~K}$. As displayed in Fig. 2c, the curve shows typical type-IV isotherms for the 700-3 porous carbon material, with a type-H2 hysteresis loop, implying the existence of both microporous and mesoporous structures in this material. Furthermore, we also used density function theory (DFT) to analyze the pore size distribution of the porous carbon materials. From Fig. 2d, we find that the 700-3 porous carbon material sample is mainly composed of mesopores with pore size 2-3 nm, while the pore volume is calculated to be about $1.53 \mathrm{~cm}^{3} \mathrm{~g}^{-1}$. The specific surface area of that material even reached $2609 \mathrm{~m}^{2} \mathrm{~g}^{-1}$, which is much larger than for previously reported porous carbon materials. ${ }^{22,28,40,41}$ Considering that both the activation temperature and addition amount of $\mathrm{KOH}$ can significantly affect the microstructure of the carbon material, the porosity structures of the obtained 700-1, 700-2, 600-3 and 800-3 samples were also investigated. As shown and listed in Fig. S3† and Table 1, all the samples possessed mesoporous structures with an average pore size of 2-3 nm; when the addition amount of $\mathrm{KOH}$ increased from $1: 1$ to $1: 3$, both the specific surface area and pore volume increased gradually. The specific surface areas were 1252, 2609 and $2262 \mathrm{~m}^{2} \mathrm{~g}^{-1}$ for $600-3,700-3$ and $800-3$, respectively, as calculated by the Brunauer-Emmett-Teller (BET) method. The lower surface area at $800{ }^{\circ} \mathrm{C}$ might be due to degradation of the carbon skeleton at such a high temperature. ${ }^{36}$ The well-developed mesoporous structure of the present carbon materials greatly improved the specific surface area and provided a high density of ion adsorption sites as well as interconnected ion diffusion pathways, which may have an enormous impact on improving charge storage and ion diffusion kinetics. ${ }^{42}$ Therefore, the porous carbon material defined as 700-3 is expected to be the ideal electrode material in supercapacitors, with the best capacitive performance.

The surface composition of the 700-3 porous carbon material was subsequently investigated by XPS analysis. As shown in Fig. 3a, three peaks ascribed to C 1s $(284.9 \mathrm{eV}), \mathrm{N} 1 \mathrm{~s}(399.9 \mathrm{eV})$ and $\mathrm{O} 1 \mathrm{~s}(531.9 \mathrm{eV})$ in the XPS survey spectrum can be observed. The XPS elemental analysis data suggest that the material contains 93.24 at\% carbon, 5.01 at\% oxygen and a small quantity of nitrogen (1.75 at\%). From the high-resolution elemental spectrum (Fig. 3b), we find that the C 1s spectrum 
(a)
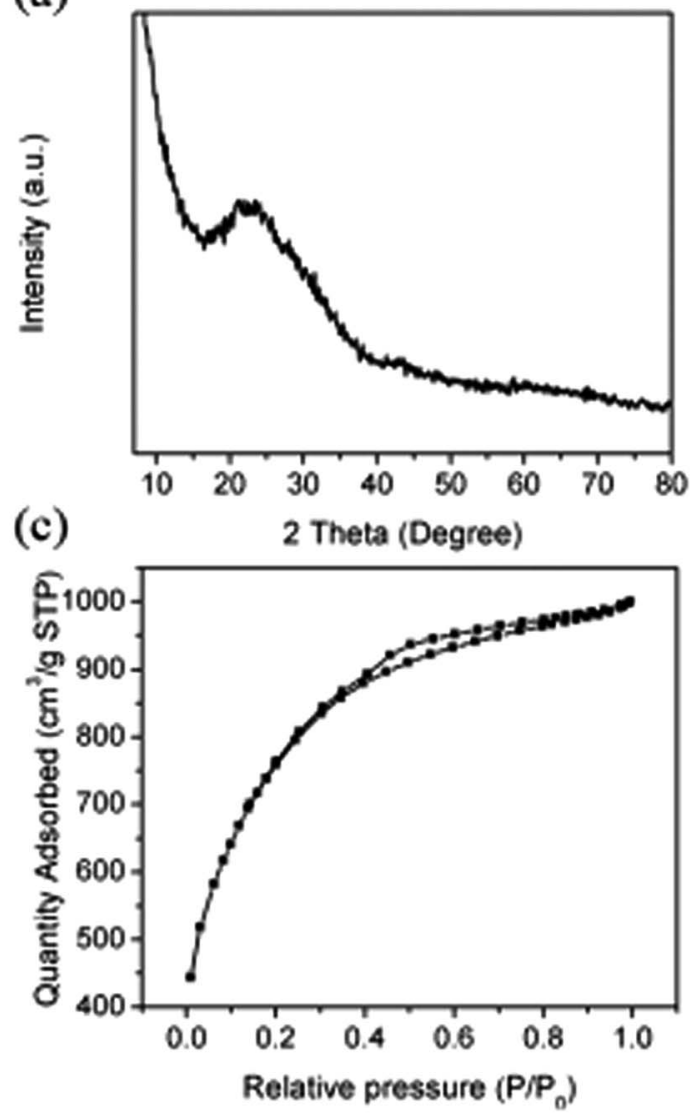

(b)
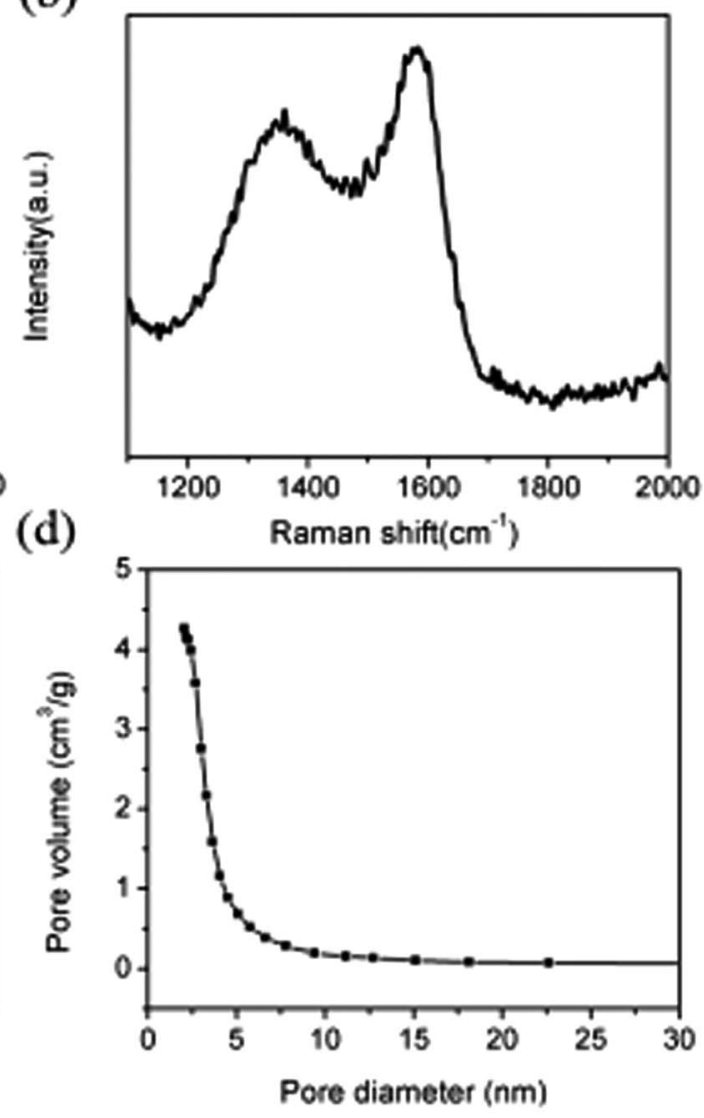

Fig. 2 (a) XRD data, (b) Raman spectrum, (c) $\mathrm{N}_{2}$ sorption-desorption isotherm and (d) pore size distribution of 700-3 sample.

can be divided into four separate peaks respectively attributed to $\mathrm{sp}^{2} \mathrm{C}=\mathrm{C}(284.3 \mathrm{eV}), \mathrm{sp}^{3} \mathrm{C}-\mathrm{C}(284.8 \mathrm{eV}), \mathrm{C}-\mathrm{O} \& \mathrm{C}-\mathrm{N}(286 \mathrm{eV})$ and $\mathrm{C}=\mathrm{O}(289 \mathrm{eV}){ }^{43-45}$ while the $\mathrm{O}$ 1s spectrum (Fig. 3c) can be fitted with two peaks that represent $\mathrm{C}=\mathrm{O}(531.6 \mathrm{eV})$ and $\mathrm{C}-\mathrm{O}$ $(533.0 \mathrm{eV}){ }^{34}$ Moreover, the nitrogen present in the prepared materials can be resolved into three species (Fig. 3d): pyridinic$\mathrm{N}$ (398.4 eV, 6.02\%), pyrrolic-N (399.94 eV, 63.17\%) and quaternary-N $(400.99 \mathrm{eV}, 30.81 \%) .{ }^{46,47}$ It has been reported that pyrrolic-N groups in a material can participate in the faradaic reactions and be a major nitrogen configuration contributing to pseudocapacitance. Meanwhile, the quaternary- $\mathrm{N}$ is believed to effectively improve the wettability of electrode material by electrolyte. ${ }^{43,48-50}$ Comparing the content of different kinds of $\mathrm{N}$ species in the C-BCS (Table 2), it is found that the sample 700-3 possesses the highest relative content of pyrrolic-N. In this way, the electrochemical performance of the 700-3 sample based electrode, such as pseudocapacitance, rate performance and cycling performance, are expected to be significantly increased and improved.

\subsection{Electrochemical performance}

Because of its hollow interconnected porous structure and abundant nitrogen- and oxygen-containing functional groups, the prepared 700-3 porous carbon sample is considered to be a suitable candidate for high performance supercapacitor electrode material. Different electrochemical performance measures, such as CV test, GCD measurement and EIS test, were performed in the three-electrode system. Fig. 4a displays the

Table 1 Characteristics of pores in C-BCS samples ${ }^{a}$

\begin{tabular}{|c|c|c|c|c|c|c|c|c|c|}
\hline Sample & $S_{\mathrm{BET}}\left(\mathrm{m}^{2} \mathrm{~g}^{-1}\right)$ & $S_{\text {mic }}\left(\mathrm{m}^{2} \mathrm{~g}^{-1}\right)$ & $S_{\text {meso }}\left(\mathrm{m}^{2} \mathrm{~g}^{-1}\right)$ & $S_{\text {meso }} / S_{\text {BET }}(\%)$ & $V_{\mathrm{T}}\left(\mathrm{cm}^{3} \mathrm{~g}^{-1}\right)$ & $V_{\text {mic }}\left(\mathrm{cm}^{3} \mathrm{~g}^{-1}\right)$ & $V_{\text {meso }}\left(\mathrm{cm}^{3} \mathrm{~g}^{-1}\right)$ & $V_{\text {meso }} / V_{\mathrm{T}}(\%)$ & $\begin{array}{l}\text { Pore size } \\
(\mathrm{nm})\end{array}$ \\
\hline $700-1$ & 1327 & 580 & 747 & 56.29 & 0.73 & 0.28 & 0.45 & 61.64 & 2.2 \\
\hline $700-2$ & 1666 & 570 & 1096 & 65.79 & 0.87 & 0.27 & 0.60 & 68.97 & 2.09 \\
\hline $700-3$ & 2609 & 847 & 1762 & 67.54 & 1.53 & 0.13 & 1.40 & 91.50 & 2.35 \\
\hline $600-3$ & 1252 & 413 & 839 & 67.01 & 0.71 & 0.13 & 0.58 & 81.69 & 2.26 \\
\hline $800-3$ & 2262 & 958 & 1304 & 57.65 & 1.84 & 0.13 & 1.71 & 92.93 & 3.25 \\
\hline
\end{tabular}

${ }^{a} S_{\mathrm{BET}}$ : specific surface area from the BET method; $V_{\mathrm{T}}$ : the total pore volume (single point adsorption at $P / P_{0}=0.97$ ); $S_{\text {mic }}$ or $S_{\text {meso }}$ : micropore or mesopore surface area; $V_{\text {mic }}$ or $V_{\text {meso }}$ : micropore or mesopore volume. 
(a)
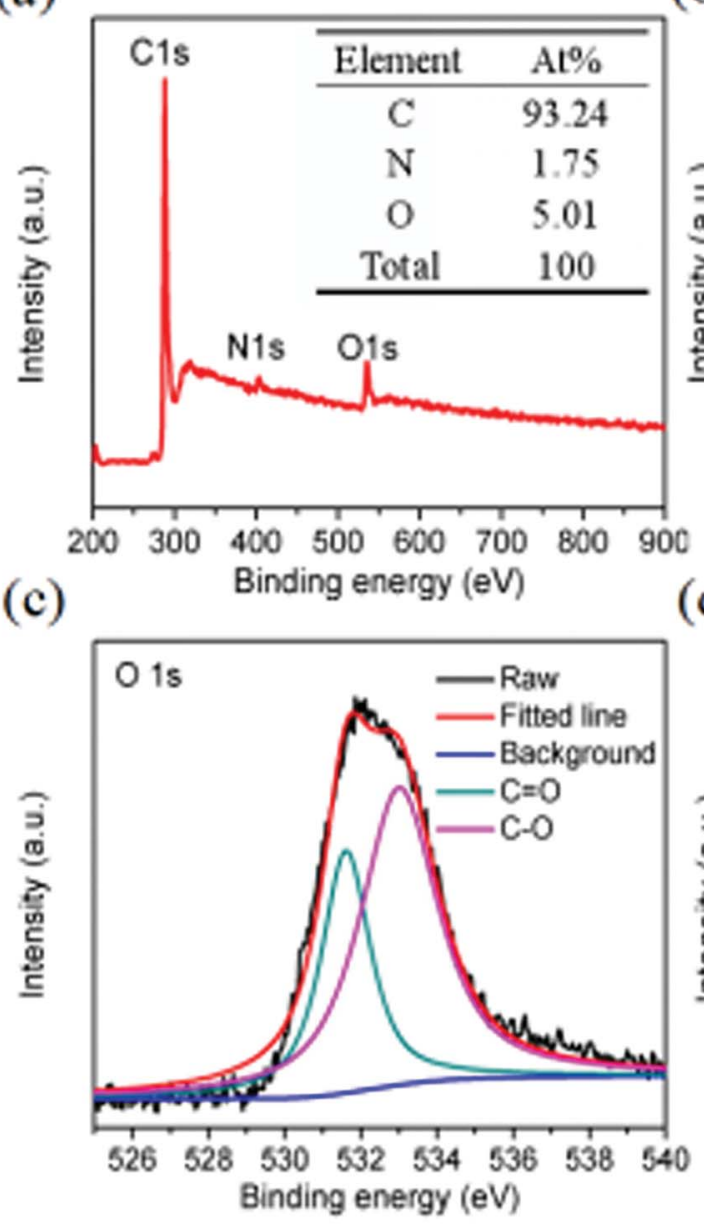

(b)

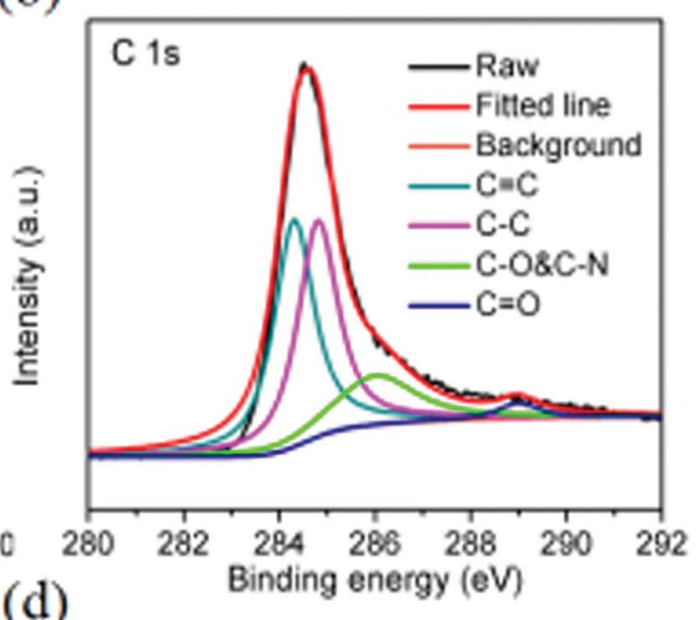

(d)

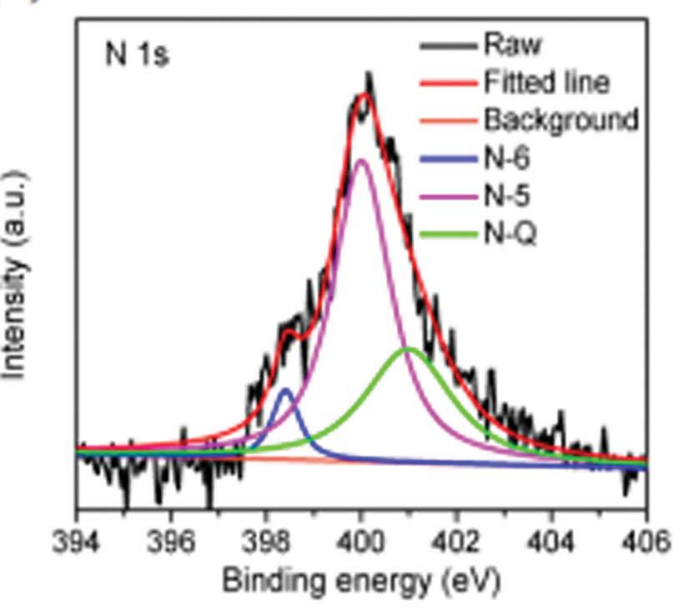

Fig. 3 (a) XPS survey spectrum and element ratio of 700-3 porous carbon material. (b)-(d) High resolution XPS spectra of $C$ s, $O 1$ s and $N$ 1s.

Table 2 The content of different kinds of $\mathrm{N}$ species in C-BCS calculated by XPS analysis

\begin{tabular}{llll}
\hline Sample & Pyridinic-N at\% & Pyrrolic-N at\% & Quaternary-N at\% \\
\hline $700-0$ & 36.95 & 30.21 & 32.84 \\
$700-1$ & 14.34 & 48.84 & 36.82 \\
$700-2$ & 12.23 & 55.86 & 31.91 \\
$700-3$ & 6.02 & 63.17 & 30.81 \\
$600-3$ & 20.38 & 47.55 & 32.07 \\
$800-3$ & - & - & - \\
\hline
\end{tabular}

variation of the $\mathrm{CV}$ curves of the 700-3 sample with gradually changing scan rates. The shape of the CV curves maintain almost symmetric rectangular shape over a wide range of scan rates, indicating the prepared $700-3$ porous carbon materials exhibited excellent electrochemical capacitive behavior. At relatively high scan rates, a small pair of redox peaks on the CV curve of the 700-3 porous carbon material can be observed, demonstrating that the total capacitance of the material is the result of a combination of double layer capacitance and pseudocapacitance. As reported in previous literature, ${ }^{18,26,27}$ the functional groups present on the 700-3 sample surface, such as $\mathrm{C}-\mathrm{N}, \mathrm{C}=\mathrm{N}$ and $\mathrm{N}-\mathrm{O}$, can effectively enhance the pseudocapacitance in aqueous electrolytes. Significantly, as compared with representative $\mathrm{CV}$ curves of other prepared carbon materials at the same scan rate of $50 \mathrm{mV} \mathrm{s}^{-1}$, the $700-3$ porous carbon material exhibits the biggest $\mathrm{CV}$ area among them (Fig. 4b). This phenomenon corresponds to the largest specific capacitance, which is associated with the high specific surface area, perfect mesoporous structure and suitable heteroatom doping factors. ${ }^{51}$

Moreover, the charge-discharge behavior of the 700-3 porous carbon material was also investigated at various current densities. As shown in Fig. 4c, many highly linear and triangularshaped charge-discharge profiles can be obtained, and almost no obvious IR drop in the GCD curve can be observed, which confirms that this material possesses high electrochemical reversibility and coulombic efficiency. The gravimetric specific capacitance of the 700-3 sample calculated from the discharge curves was $405,351.5,330$ and $318.6 \mathrm{~F} \mathrm{~g}^{-1}$, corresponding to a current density of $0.5,1,2$ and $3 \mathrm{~A} \mathrm{~g}^{-1}$, respectively. Also, even at the relatively high current density of $20 \mathrm{~A} \mathrm{~g}^{-1}$, the specific capacitance was maintained at $274 \mathrm{~F} \mathrm{~g}^{-1}$ (retained $67.65 \%$ of its initial capacitance, Fig. 4d), which is much better than most of 
(a)

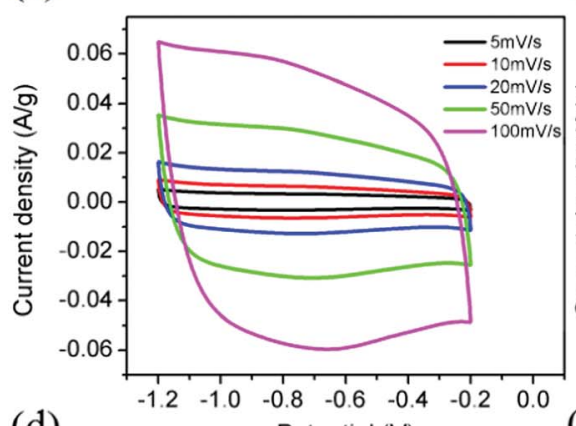

(d)

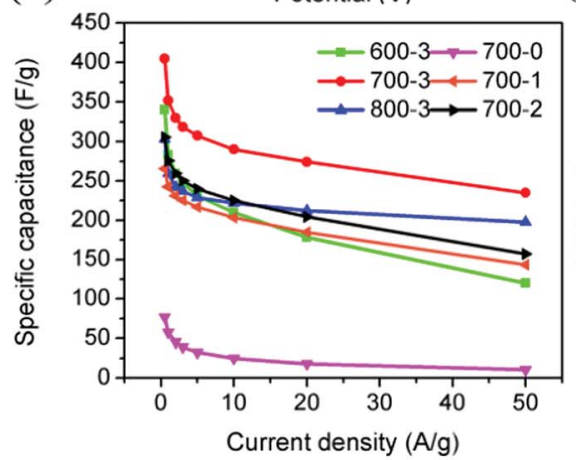

(b)

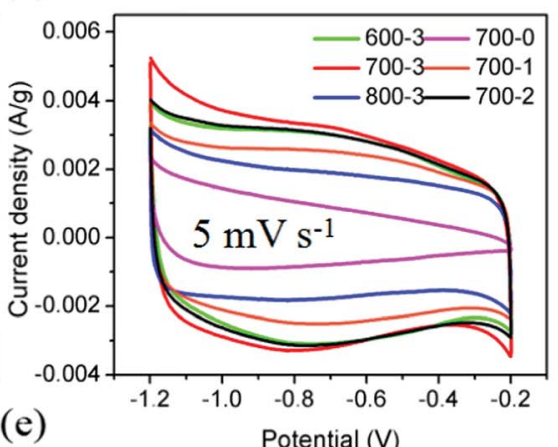

(e)
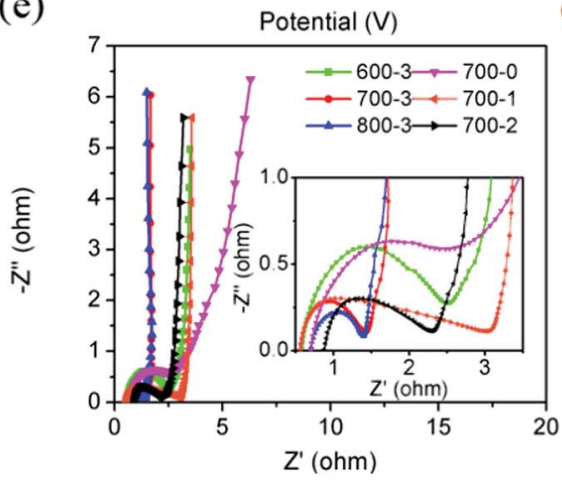

(c)

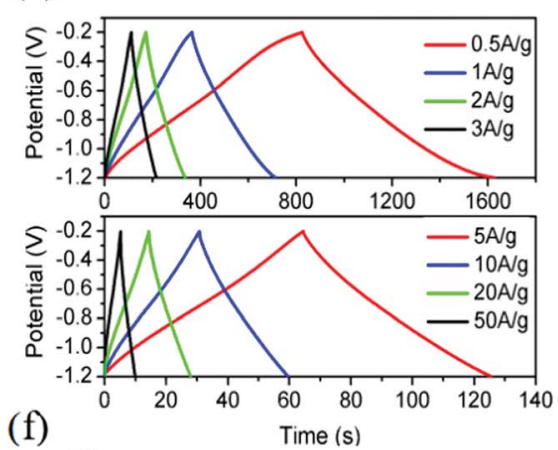

(f)

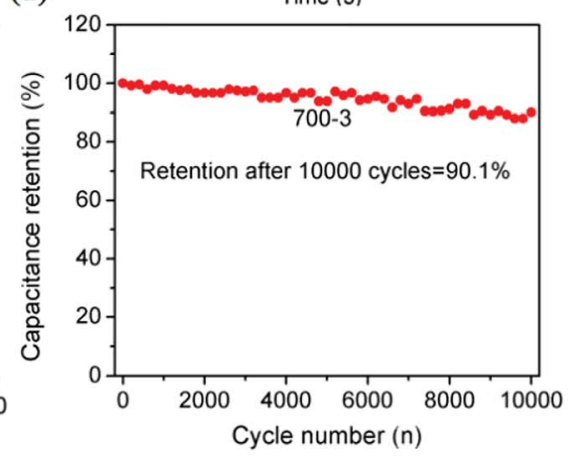

Fig. 4 Electrochemical tests on C-BCS measured in $6 \mathrm{M} \mathrm{KOH}$. (a) CV curves of 700-3 sample at different scan rates. (b) CV curves of different CBCS at a scan rate of $5 \mathrm{mV} \mathrm{s}^{-1}$. (c) GCD curves of 700-3 sample at different current densities. (d) Rate performance at different current densities. (e) Electrochemical impedance spectra of C-BCS. The inset shows the magnified region of $0.5-3.5 \Omega$. (f) Cyclic stability of $700-3$ at a chargedischarge current density of $5 \mathrm{~A} \mathrm{~g}^{-1}$ for 10000 cycles.

previous reported porous carbon materials derived from biomass (Table 3).

EIS measurements were also employed to evaluate the internal resistance of the material as well as the resistance in charge transfer and ion diffusion processes of supercapacitors. ${ }^{52,53}$ Fig. 4e shows the Nyquist plots collected in $6 \mathrm{M}$ $\mathrm{KOH}$ in the frequency range of $0.1 \mathrm{~Hz}$ to $100 \mathrm{kHz}$ with an amplitude of $5 \mathrm{mV}$. It is found that the slope curves of all the remaining samples in the low frequency region are near to $90^{\circ}$, except for the 700-0 sample, indicating that the activated carbon electrodes are porous and have the capacitive characteristics of an ideal capacitor. As the weight ratio between carbonaceous samples and $\mathrm{KOH}$ increases, the capacitance characteristics of the activated carbon electrode become better. The semicircular arc in the high-frequency region simultaneously reflects the bulk properties of the electrode and electrolyte and the charge transfer at the electrode/electrolyte interface. Comparing the semicircular diameters of the high-frequency portions of the six impedance curves in the inset figure, it can be found that the $R_{\mathrm{ct}}$ increases gradually as the carbonization temperature or the weight ratio between carbonaceous samples and $\mathrm{KOH}$ increases. According to the previous studies ${ }^{42}$ and the obtained data listed in Table 1, the mesopore structure obtained by activation is at its most when the ratio of alkali to carbon is $3: 1$, which can give rise to a small charge transfer resistance. Similarly, when the ratio of alkali to carbon is lower, the micropore

Table 3 Comparison of various biomass-derived porous carbon materials in supercapacitor applications

\begin{tabular}{|c|c|c|c|c|c|}
\hline Precursor & $S_{\text {BET }}\left(\mathrm{m}^{2} \mathrm{~g}^{-1}\right)$ & $\begin{array}{l}\text { Current density } \\
\left(\mathrm{A} \mathrm{g}^{-1}\right)\end{array}$ & $C_{\mathrm{g}}\left(\mathrm{F} \mathrm{g}^{-1}\right)$ & Electrolyte & Ref. \\
\hline Yogurt & 1300 & 2 & 225 & $1 \mathrm{M} \mathrm{H}_{2} \mathrm{SO}_{4}$ & 11 \\
\hline Auricularia & 1607 & 1 & 347 & $6 \mathrm{M} \mathrm{KOH}$ & 26 \\
\hline Soybean & 350 & $10 \mathrm{mV} \mathrm{s}^{-1}$ & 315 & $6 \mathrm{M} \mathrm{KOH}$ & 27 \\
\hline Tofu & 1208 & 0.5 & 262 & $1 \mathrm{M} \mathrm{Na}_{2} \mathrm{SO}_{4}$ & 28 \\
\hline Kiwifruit & 379.0 & 0.5 & 337.4 & $6 \mathrm{M} \mathrm{KOH}$ & 34 \\
\hline Jujun grass & 2532 & 1 & 336 & $6 \mathrm{M} \mathrm{KOH}$ & 36 \\
\hline Wheat straw & 1201 & $5 \mathrm{mV} \mathrm{s}^{-1}$ & 223.9 & $6 \mathrm{M} \mathrm{KOH}$ & 38 \\
\hline Dead pine needles & 783 & 0.5 & 223 & $1 \mathrm{M} \mathrm{H}_{2} \mathrm{SO}_{4}$ & 39 \\
\hline Bean curd stick & 2609 & 0.5 & 405 & $6 \mathrm{M} \mathrm{KOH}$ & This work \\
\hline
\end{tabular}


(a)

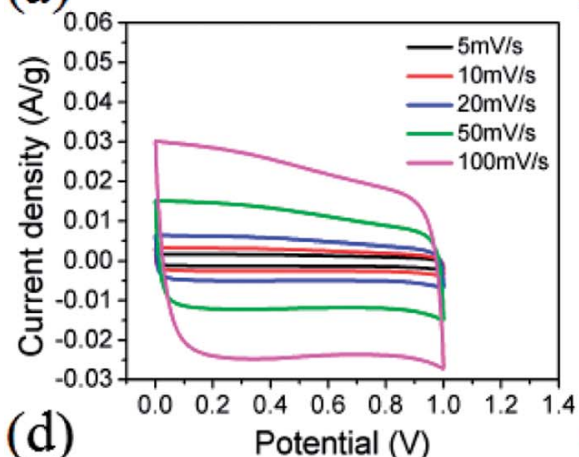

(d)

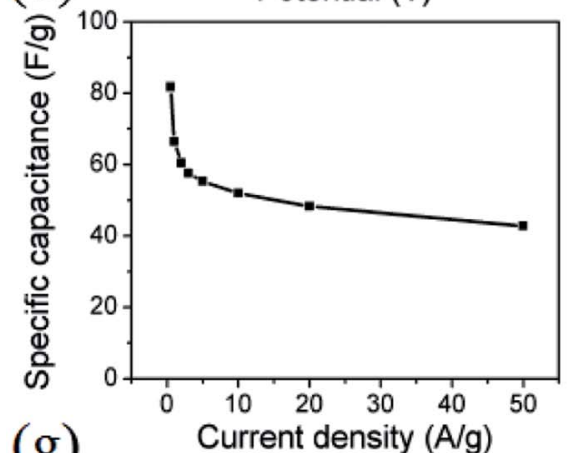

(g)

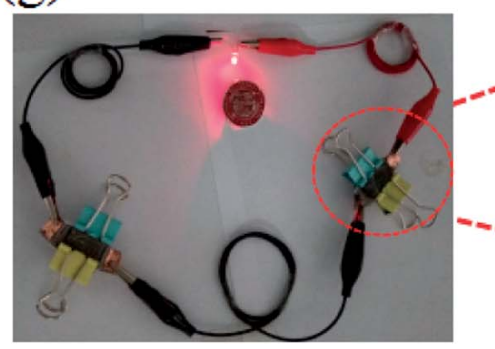

(b)

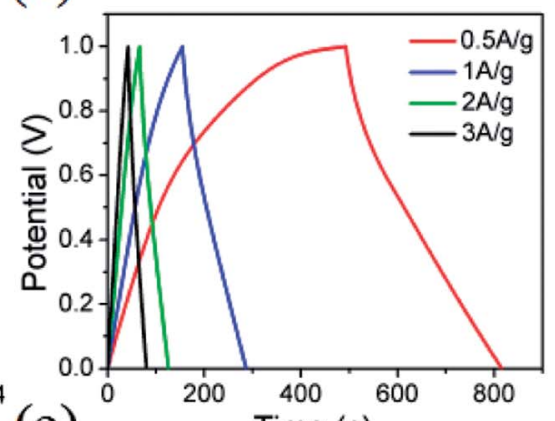

(e)

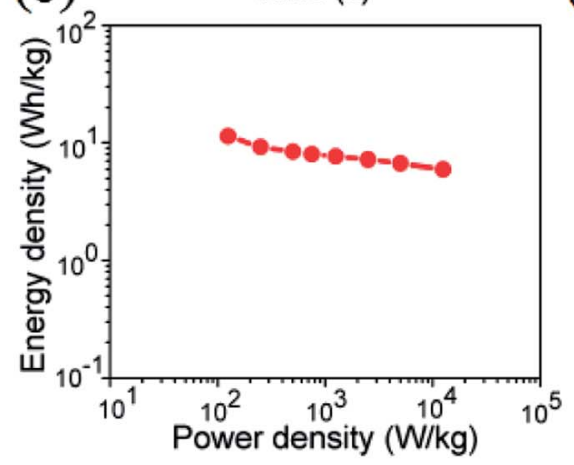

(c)
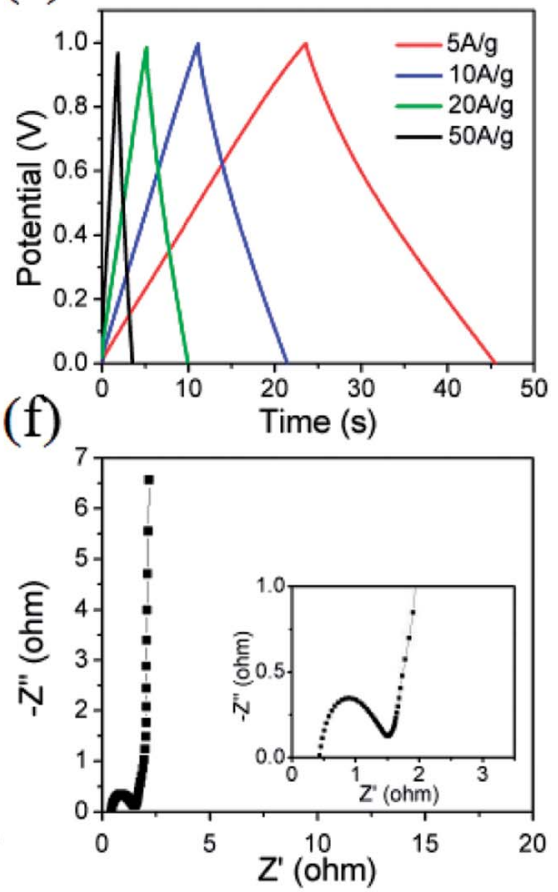

Fig. 5 Electrochemical experiments using the 700-3//700-3 symmetric supercapacitor. (a) CV test at different scan rates. (b) and (c) GCD test at different current densities. (d) Rate performance with different current densities. (e) Ragone plot of 700-3 based symmetrical supercapacitor. (f) EIS measurement of the symmetric supercapacitor. The inset shows the magnified region of $0.5-3.5 \Omega$. (g) Red LED powered by the fabricated device and schematic illustration of the fabricated symmetric two-electrode supercapacitor.

structure of activated carbon increases gradually, so the charge transfer resistance is greater. The 700-3 sample possesses the smallest charge transfer resistance and the fastest charge/ discharge rate, and therefore has the better capacitive characteristics. Furthermore, we also investigated the long-term cyclic stability of the 700-3 porous carbon materials based electrode. By using GCD measurement at a current density of $5 \mathrm{~A} \mathrm{~g}^{-1}$ within the potential range of -1.2 to $-0.2 \mathrm{~V} v s$. SCE, we observed only a slight variation of specific capacitance with the increase of cycle number and the remaining capacitance was 90.1\% after 10000 cycles (Fig. 4f), which indicated that the electrode possesses an excellent charge/discharge stability.

In order to further explore the 700-3 porous carbon material for practical supercapacitor applications, the capacitive performance of a two-electrode symmetric supercapacitor containing the 700-3 sample was also evaluated. As displayed in Fig. 5a, the $\mathrm{CV}$ curves exhibited typical capacitive behavior with rectangular-like voltammetry characteristics, and possessed an ideal capacitive behavior consistent with the result for the threeelectrode system. Besides, for GCD measurement, no obvious IR drop could be observed with the linear and nearly symmetric triangular curves, suggesting good capacitive behavior of the 700-3 sample based supercapacitor (Fig. $5 \mathrm{~b}$ and c). The specific capacitance of the supercapacitor was calculated to be $81.7 \mathrm{~F}$ $\mathrm{g}^{-1}$ at $0.5 \mathrm{~A} \mathrm{~g}^{-1}$ and $42.8 \mathrm{~F} \mathrm{~g}^{-1}$ at $50 \mathrm{~A} \mathrm{~g}^{-1}$ (Fig. 5d), while the capacitance retention was $52.4 \%$. Fig. 5e displays the Ragone plot of the assembled 700-3 sample based symmetric supercapacitor. As shown, the present symmetric supercapacitor delivered a maximum energy density of $11.35 \mathrm{~W} \mathrm{~h} \mathrm{~kg}^{-1}$ at a power density of $125 \mathrm{~W} \mathrm{~kg}^{-1}$, and $5.94 \mathrm{~W} \mathrm{~h} \mathrm{~kg}^{-1}$ still remained even at a high power density of $12500 \mathrm{~W} \mathrm{~kg}^{-1}$. This obtained maximum energy density value is comparable to or even better than the commercial devices $\left(<5 \mathrm{~W} \mathrm{~h} \mathrm{~kg}^{-1}\right)^{54,55}$ and other previously reported carbon-based symmetric supercapacitors in aqueous electrolyte, such as those based on yogurt $\left(7 \mathrm{~W} \mathrm{~h} \mathrm{~kg}{ }^{-1}\right),{ }^{11}$ lignin $\left(8.34 \mathrm{~W} \mathrm{~h} \mathrm{~kg}{ }^{-1}\right),{ }^{56}$ wild jujube pit $\left(8.95 \mathrm{~W} \mathrm{~h} \mathrm{~kg}^{-1}\right),{ }^{57}$ pomelo peel $\left(9.4 \mathrm{~W} \mathrm{~h} \mathrm{~kg}^{-1}\right){ }^{34}$ bamboo byproduct $\left.(9.5 \mathrm{~W} \mathrm{~h} \mathrm{~kg})^{-1}\right)^{22}$ and soybean curd residue $\left(9.95 \mathrm{~W} \mathrm{~h} \mathrm{~kg}^{-1}\right) \cdot{ }^{27}$ Such excellent performance of the capacitor is due mainly to the large specific surface area, interconnected 
porous structure and efficient N-doped structure of 700-3. On the one hand, the doped nitrogen heteroatom in the carbon skeleton can effectively increase its wettability and induce pseudocapacitance behavior; ${ }^{\mathbf{4 8}}$ on the other, the unique pore size distribution in the material would provide a well-defined diffusion pathway for ions and electrons. ${ }^{51}$ The EIS measurement also revealed that the symmetric supercapacitor has small ionic resistance of the electrolyte $(1.07 \Omega)$, and the near-vertical slope curve in the low frequency region also indicates that the supercapacitor has excellent capacitance characteristics (Fig. 5f). Furthermore, two devices connected in tandem can also power a $2.5 \mathrm{~V}$ red light-emitting diode (LED) (Fig. 5g), indicating that $700-3$ porous carbon is a promising electrode material for supercapacitors.

\section{Conclusions}

In summary, we successfully synthesized a heteroatom-doped porous carbon structure from the byproduct (slag material) of the bean curd stick manufacturing process. The present carbon material not only possesses a large specific surface area (2609 $\mathrm{m}^{2} \mathrm{~g}^{-1}$ ) but also has an outstanding capacitive performance with high capacitance and superior cycle stability. Remarkably, the 700-3 porous carbon materials based symmetric capacitor also manifests a high energy density of $11.35 \mathrm{~W} \mathrm{~h} \mathrm{~kg}^{-1}$, which is comparable to or much better than the commercially available devices and other previously reported carbon-based symmetric supercapacitors in aqueous electrolyte. The present work not only provides a novel biomass- derived porous carbon material for future high-performance supercapacitors applications, but also can add great secondary-utilization value to the byproduct of bean curd stick manufacture.

\section{Conflicts of interest}

There are no conflicts to declare.

\section{Acknowledgements}

This work was supported by the National Natural Science Foundation of China (21305110), the Young Talent Lifting Plan of Association for Science and Technology of Shaanxi (20160215), Shaanxi Provincial Department of Education Natural Science Special Project (17JK0778) and Scholar Tang.

\section{References}

1 L. L. Zhang and X. S. Zhao, Carbon-based materials as supercapacitor electrodes, Chem. Soc. Rev., 2009, 38, 25202531.

2 H. Jiang, P. S. Lee and C. Li, 3D carbon based nanostructures for advanced supercapacitors, Energy Environ. Sci., 2013, 6, 41-53.

3 X. Lai, J. E. Halpert and D. Wang, Recent advances in micro-/ nano-structured hollow spheres for energy applications: from simple to complex systems, Energy Environ. Sci., 2012, 5, 5604-5618.
4 L. Dai, D. W. Chang, J. B. Baek and W. Lu, Carbon nanomaterials for advanced energy conversion and storage, Small, 2012, 8, 1130-1166.

5 Z. Niu, H. Dong, B. Zhu, J. Li, H. H. Hng, W. Zhou, X. Chen and S. Xie, Highly stretchable, integrated supercapacitors based on single-walled carbon nanotube films with continuous reticulate architecture, Adv. Mater., 2013, 25, 1058-1064.

6 A. Burke, Ultracapacitors: why, how, and where is the technology, J. Power Sources, 2000, 91, 37-50.

7 Z. Wu, L. Li, J. M. Yan and X. B. Zhang, Materials design and system construction for conventional and new-concept supercapacitors, Adv. Sci., 2017, 4, 1600382.

8 S. Liu, K. H. Kim, J. M. Yun, A. Kundu, K. V. Sankar, U. M. Patil, C. Ray and S. Chan Jun, 3D yolk-shell NiGa $\mathrm{S}_{4}$ microspheres confined with nanosheets for high performance supercapacitors, J. Mater. Chem. A, 2017, 5, 6292-6298.

9 A. M. Elshahawy, X. Li, H. Zhang, Y. Hu, K. H. Ho, C. Guan and J. Wang, Controllable $\mathrm{MnCo}_{2} \mathrm{~S}_{4}$ nanostructures for high performance hybrid supercapacitors, J. Mater. Chem. A, 2017, 5, 7494-7506.

10 Y. B. Tan and J.-M. Lee, Graphene for supercapacitor applications, J. Mater. Chem. A, 2013, 1, 14814.

11 M. Wahid, G. Parte, D. Phase and S. Ogale, Yogurt: a novel precursor for heavily nitrogen doped supercapacitor carbon, J. Mater. Chem. A, 2015, 3, 1208-1215.

12 W. Zhang, H. Lin, Z. Lin, J. Yin, H. Lu, D. Liu and M. Zhao, 3D hierarchical porous carbon for supercapacitors prepared from lignin through a facile template-free method, ChemSusChem, 2015, 8, 2114-2122.

13 M. M. Islam, C. M. Subramaniyam, T. Akhter, S. N. Faisal, A. I. Minett, H. K. Liu, K. Konstantinov and S. X. Dou, Three dimensional cellular architecture of sulfur doped graphene: self-standing electrode for flexible supercapacitors, lithium ion and sodium ion batteries, $J$. Mater. Chem. A, 2017, 5, 5290-5302.

$14 \mathrm{H}$. Lu and X. S. Zhao, Biomass-derived carbon electrode materials for supercapacitors, Sustainable Energy Fuels, 2017, 1, 1265-1281.

15 A. M. Abioye and F. N. Ani, Recent development in the production of activated carbon electrodes from agricultural waste biomass for supercapacitors: a review, Renewable Sustainable Energy Rev., 2015, 52, 1282-1293.

16 H. Zhang, H. Su, L. Zhang, B. Zhang, F. Chun, X. Chu, W. He and W. Yang, Flexible supercapacitors with high areal capacitance based on hierarchical carbon tubular nanostructures, J. Power Sources, 2016, 331, 332-339.

17 M. Gopiraman, D. Deng, B.-S. Kim, I.-M. Chung and I. S. Kim, Three-dimensional cheese-like carbon nanoarchitecture with tremendous surface area and pore construction derived from corn as superior electrode materials for supercapacitors, Appl. Surf. Sci., 2017, 409, 52-59.

18 B. Liu, Y. Liu, H. Chen, M. Yang and H. Li, Oxygen and nitrogen co-doped porous carbon nanosheets derived from 
Perilla frutescens for high volumetric performance supercapacitors, J. Power Sources, 2017, 341, 309-317.

19 C.-S. Yang, Y. S. Jang and H. K. Jeong, Bamboo-based activated carbon for supercapacitor applications, Curr. Appl. Phys., 2014, 14, 1616-1620.

20 Y.-P. Huang, C.-H. Hou, H.-C. Hsi and J.-W. Wu, Optimization of highly microporous activated carbon preparation from Moso bamboo using central composite design approach, J. Taiwan Inst. Chem. Eng., 2015, 50, 266275.

21 H. Chen, D. Liu, Z. Shen, B. Bao, S. Zhao and L. Wu, Functional biomass carbons with hierarchical porous structure for supercapacitor electrode materials, Electrochim. Acta, 2015, 180, 241-251.

22 W. Tian, Q. Gao, Y. Tan, K. Yang, L. Zhu, C. Yang and H. Zhang, Bio-inspired beehive-like hierarchical nanoporous carbon derived from bamboo-based industrial byproduct as a high performance supercapacitor electrode material, J. Mater. Chem. A, 2015, 3, 5656-5664.

$23 \mathrm{~J}$. Li, S. Ma, L. Cheng and Q. Wu, Egg yolk-derived threedimensional porous carbon for stable electrochemical supercapacitors, Mater. Lett., 2015, 139, 429-432.

$24 \mathrm{H}$. Zhu, X. Wang, F. Yang and X. Yang, Promising carbons for supercapacitors derived from fungi, Adv. Mater., 2011, 23, 2745-2748.

25 C. Long, X. Chen, L. Jiang, L. Zhi and Z. Fan, Porous layerstacking carbon derived from in-built template in biomass for high volumetric performance supercapacitors, Nano Energy, 2015, 12, 141-151.

26 L. Jiang, L. Sheng, X. Chen, T. Wei and Z. Fan, Construction of nitrogen-doped porous carbon buildings using interconnected ultra-small carbon nanosheets for ultrahigh rate supercapacitors, J. Mater. Chem. A, 2016, 4, 11388-11396.

27 G. Ma, F. Ran, H. Peng, K. Sun, Z. Zhang, Q. Yang and Z. Lei, Nitrogen-doped porous carbon obtained via onestep carbonizing biowaste soybean curd residue for supercapacitor applications, RSC Adv., 2015, 5, 83129-83138.

28 T. Ouyang, K. Cheng, F. Yang, L. Zhou, K. Zhu, K. Ye, G. Wang and D. Cao, From biomass with irregular structures to $1 \mathrm{D}$ carbon nanobelts: a stripping and cutting strategy to fabricate high performance supercapacitor materials, J. Mater. Chem. A, 2017, 5, 14551-14561.

29 N. Guo, M. Li, Y. Wang, X. Sun, F. Wang and R. Yang, Soybean root-derived hierarchical porous carbon as electrode material for high-performance supercapacitors in ionic liquids, ACS Appl. Mater. Interfaces, 2016, 8, 3362633634.

30 Z. Chen, X. Zhou, C. Song, C. Mei, J. Xu and S. Zhou, Evaluating biomass-derived hierarchically porous carbon as the positive electrode material for hybrid Na-ion capacitors, J. Power Sources, 2018, 440, 1027-1036.

31 Y. Deng, Y. Xie, K. Zou and X. Ji, Review on recent advances in nitrogen-doped carbons: preparations and applications in supercapacitors, J. Mater. Chem. A, 2016, 4, 1144-1173.

32 R. Wang, P. Wang, X. Yan, J. Lang, C. Peng and Q. Xue, Promising porous carbon derived from celtuce leaves with outstanding supercapacitance and $\mathrm{CO}_{2}$ capture performance, ACS Appl. Mater. Interfaces, 2012, 4, 5800-5806.

33 J. Chang, Z. Gao, X. Liu, D. Wu, F. Xu, Y. Guo, Y. Guo and K. Jiang, Hierarchically porous carbons with graphene incorporation for efficient supercapacitors, Electrochim. Acta, 2016, 213, 382.

34 Q. Liang, L. Ye, Z. H. Huang, Q. Xu, Y. Bai, F. Kang and Q. H. Yang, A honeycomb-like porous carbon derived from pomelo peel for use in high-performance supercapacitors, Nanoscale, 2014, 6, 13831-13837.

35 V. Zólyomi, J. Koltai and J. Kürti, Resonance Raman spectroscopy of graphite and graphene, Phys. Status Solidi $B, 2011,248,2435-2444$.

36 C. Wang, Y. Xiong, H. Wang, C. Jin and Q. Sun, Naturally three-dimensional laminated porous carbon network structured short nano-chains bridging nanospheres for energy storage, J. Mater. Chem. A, 2017, 5, 15759-15770.

37 Y. S. Yun, M. H. Park, S. J. Hong, M. E. Lee, Y. W. Park and H. J. Jin, Hierarchically porous carbon nanosheets from waste coffee grounds for supercapacitors, ACS Appl. Mater. Interfaces, 2015, 7, 3684-3690.

38 Y. Liu, B. Huang, X. Lin and Z. Xie, Biomass-derived hierarchical porous carbons: boosting the energy density of supercapacitors via an ionothermal approach, J. Mater. Chem. A, 2017, 5, 13009-13018.

39 W. Qian, F. Sun, Y. Xu, L. Qiu, C. Liu, S. Wang and F. Yan, Human hair-derived carbon flakes for electrochemical supercapacitors, Energy Environ. Sci., 2014, 7, 379-386.

40 S. Zhang, K. Tian, B.-H. Cheng and H. Jiang, Preparation of $\mathrm{N}$-doped supercapacitor materials by integrated salt templating and silicon hard templating by pyrolysis of biomass wastes, ACS Sustainable Chem. Eng., 2017, 5, 66826691.

41 C. Leng, K. Sun, J. Li and J. Jiang, From dead pine needles to $\mathrm{O}, \mathrm{N}$ codoped activated carbons by a one-step carbonization for high rate performance supercapacitors, ACS Sustainable Chem. Eng., 2017, 5, 10474-10482.

42 D.-D. Zhou, W.-Y. Li, X.-L. Dong, Y.-G. Wang, C.-X. Wang and Y.-Y. Xia, A nitrogen-doped ordered mesoporous carbon nanofiber array for supercapacitors, J. Mater. Chem. A, 2013, 1, 8488.

43 D. Puthusseri, V. Aravindan, S. Madhavi and S. Ogale, 3D micro-porous conducting carbon beehive by single step polymer carbonization for high performance supercapacitors: the magic of in situ porogen formation, Energy Environ. Sci., 2014, 7, 728-735.

44 T. Wei, X. Wei, Y. Gao and H. Li, Large scale production of biomass-derived nitrogen-doped porous carbon materials for supercapacitors, Electrochim. Acta, 2015, 169, 186-194.

45 C. Long, J. Zhuang, Y. Xiao, M. Zheng, H. Hu, H. Dong, B. Lei, H. Zhang and Y. Liu, Nitrogen-doped porous carbon with an ultrahigh specific surface area for superior performance supercapacitors, J. Power Sources, 2016, 310, 145-153.

46 L. F. Chen, Z. H. Huang, H. W. Liang, Q. F. Guan and S. H. Yu, Bacterial-cellulose-derived carbon nanofiber @ $\mathrm{MnO}_{2}$ and nitrogen-doped carbon nanofiber electrode 
materials: an asymmetric supercapacitor with high energy and power density, Adv. Mater., 2013, 25, 4746-4752.

47 R. Pietrzak, XPS study and physico-chemical properties of nitrogen-enriched microporous activated carbon from high volatile bituminous coal, Fuel, 2009, 88, 1871-1877.

48 D. Usachov, O. Vilkov, A. Gruneis, D. Haberer, A. Fedorov, V. K. Adamchuk, A. B. Preobrajenski, P. Dudin, A. Barinov, M. Oehzelt, C. Laubschat and D. V. Vyalikh, Nitrogendoped graphene: efficient growth, structure, and electronic properties, Nano Lett., 2011, 11, 5401-5407.

49 C. Chen, D. Yu, G. Zhao, B. Du, W. Tang, L. Sun, Y. Sun, F. Besenbacher and M. Yu, Three-dimensional scaffolding framework of porous carbon nanosheets derived from plant wastes for high-performance supercapacitors, Nano Energy, 2016, 27, 377-389.

50 J. Jiang, J. Zhu, W. Ai, Z. Fan, X. Shen, C. Zou, J. Liu, H. Zhang and T. Yu, Evolution of disposable bamboo chopsticks into uniform carbon fibers: a smart strategy to fabricate sustainable anodes for Li-ion batteries, Energy Environ. Sci., 2014, 7, 2670-2679.

51 D. C. Guo, J. Mi, G.-P. Hao, W. Dong, G. Xiong, W.-C. Li and A.-H. Lu, Ionic liquid $\mathrm{C}_{16} \mathrm{mimBF}_{4}$ assisted synthesis of poly(benzoxazine-co-resol)-based hierarchically porous carbons with superior performance in supercapacitors, Energy Environ. Sci., 2013, 6, 652-659.
$52 \mathrm{~J}$. Zhang and X. S. Zhao, On the configuration of supercapacitors for maximizing electrochemical performance, ChemSusChem, 2012, 5, 818-841.

53 G. Zheng, L. Hu, H. Wu, X. Xie and Y. Cui, Paper supercapacitors by a solvent-free drawing method, Energy Environ. Sci., 2011, 4, 3368.

54 A. Burke, R\&D considerations for the performance and application of electrochemical capacitors, Electrochim. Acta, 2007, 53, 1083-1091.

55 Y. Zhu, S. Murali, M. D. Stoller, K. J. Ganesh, W. Cai, P. J. Ferreira, A. Pirkle, R. M. Wallace, K. A. Cychosz, M. Thommes, D. Su, E. A. Stach and R. S. Ruoff, Carbonbased supercapacitors produced by activation of graphene, Science, 2011, 332, 1537-1541.

56 D. Saha, Y. Li, Z. Bi, J. Chen, J. K. Keum, D. K. Hensley, H. A. Grappe, H. M. Meyer III, S. Dai, M. P. Paranthaman and A. K. Naskar, Studies on supercapacitor electrode material from activated lignin-derived mesoporous carbon, Langmuir, 2014, 30, 900-910.

57 K. Sun, S. Yu, Z. Hu, Z. Li, G. Lei, Q. Xiao and Y. Ding, Oxygen-containing hierarchically porous carbon materials derived from wild jujube pit for high-performance supercapacitor, Electrochim. Acta, 2017, 231, 417-428. 